\title{
Recurrence of suicidal thoughts and behaviors during one year of follow- up: An exploratory study.
}

\author{
Authors: \\ Paula Suárez-Pinilla ${ }^{a} b^{*}+$, Marina Pérez-Herrera ${ }^{a}$, Marta Suárez-Pinilla ${ }^{c \dagger}$, Raquel Medina-Blanco ${ }^{a}$, \\ Enrique López-García a, Jesús Ángel Artal-Simón ${ }^{a}$, Ana Isabel de Santiago-Díaz a* \\ a Department of Psychiatry, University Hospital Marqués de Valdecilla, IDIVAL, Santander, Spain \\ ${ }^{b}$ Centro de Investigación Biomédica en Red de Salud Mental (CIBERSAM), Santander, Spain \\ ' Department of Neurodegenerative Diseases, UCL, $n$ Queen Square Institute of Neurology, \\ London, UK.
}

† Paula Suárez-Pinilla and Marta Suárez-Pinilla have equally contributed to this work.

${ }^{*}$ Corresponding author: Dra. Paula Suárez-Pinilla. Department of Psychiatry, University Hospital Marqués de Valdecilla. Avda Valdecilla s/n, 39008, Santander, Spain. Tel: +34 6760466 24. Email: p.suarez.pinilla@gmail.com

Co-corresponding author: Dra. Ana Isabel de Santiago-Díaz. Department of Psychiatry, University Hospital Marqués de Valdecilla. Avda Valdecilla s/n, 39008, Santander, Spain. Tel. +34 6010445 48. E-mail: anaisabelde.santiago@scsalud.es 


\begin{abstract}
Suicidal thoughts and behaviors (STB) include suicidal ideation (SI), suicide attempt (SA) and completed suicide. We aimed to identify recurrence predictors of any type of STB, and separately for SA and SI, and to analyze the time until event. A 108-subject cohort presenting at Emergencies with STB was followed during one year. Recurrence risk factors were investigated by multiple Cox survival regressions. Within one year, $31.5 \%, 23.1 \%$ and $9.3 \%$ patients recurred with any STB, SA, and SI respectively. Most recurrences ( 70\%) occurred within the first 6 months. Seeking emergency psychiatric assistance for problems other than STB during follow-up was a common predictor for recurrence of any STB, and SA and SI specifically. Previous SA history and contact with psychiatry outpatient units during follow-up predicted both STB in general and SA in particular. A specific predictor for SA was hospitalization at index, while SI recurrence was associated to SI at index. These results highlight the importance of early intervention and multidisciplinary follow-up considering concurrent psychosocial or adaptive problems. A careful exploration at Emergencies is needed to target potential predictors.
\end{abstract}

Keywords: Suicide; Self-injurious behavior; Suicidal thoughts and behaviors; Attempted suicide; Suicidal ideation; Cohort study; Follow-up studies; Risk factors; Secondary prevention 


\section{HIGHLIGHTS}

- $31.5 \%$ patients with suicidal thoughts or behaviors recurred in 1-year follow-up.

- Around $70 \% \%$ of recurrences occurred in the first 6 months.

- Seeking psychiatric help for non-STB reasons was a common predictor for all STB.

- Previous attempts and hospitalization after index episode predicted re-attempts.

- Suicidal ideation at the index predicted recurrence in the form of suicidal ideation. 


\section{Introduction}

Suicidal thoughts and behaviors (STB) constitute a serious problem in public healthcare services and a global issue in both general and psychiatric populations. A very complex and heterogeneous range of phenomena, STB comprise thinking about suicide with or without specific planning (suicidal ideation, $\mathrm{SI}$ ), attempting suicide (suicide attempt, SA) and death by suicide (or completed suicide) (Posner, 2007)(American Psychiatric Association, 2003). The World Health Organization estimates that near 800,000 people die by suicide every year (World Health Organization, 2014), yet rates of SA and (to an even greater extent) SI are far more common. Although statistics on the incidence of such phenomena are conflicting due to the difficulty of exhaustively identifying less severe cases, as well as divergent methodology and definitions used in the different studies (Ros and Arranz, 2015)(Schmidtke, 1997), it is estimated that the ratio between completed suicide, SA, and $\mathrm{SI}$ is approximately 1:10:100 (McAuliffe, 2002).

It has been noted that about one third of people with SI will eventually attempt suicide (Nock et al., 2008), and history of previous SA is the single more important predictor for completed suicide, present in $40 \%$ of such cases (World Health Organization, 2014)(Hawton and van Heeringen, 2009)(Cavanagh et al., 2003). Yet an individualized assessment and stratification of the risk associated with different types of STB remains a complicated task. By its own nature, SI is fully dependent on self-report and very often goes unnoticed (World Health Organization, 2014). As for $\mathrm{SA}$, unfortunately, there are no uniform and operational definitions and the terminology referring to self-injurious behaviors without death outcome is different depending on the country (Skegg, 2005). Several criteria have been proposed and the American Psychiatric Association has included the suicidal behavior disorder as a separate entity in the Section III "conditions for further study" of the latest version of the Diagnostic and Statistical Manual for Mental Disorders (DSM-5). Following this criterion, SA is defined as a sequence of actions initiated by a person who expects a lethal outcome (American Psychiatric Association, 2013).

To date, several authors have approached the study of risk factors for SA through the examination of participants with a history of SA using retrospective (Gallego et al., 2015), cross-sectional (Liu et al., 2017) or prospective designs (Bhaskaran et al., 2014)(Murphy et al., 2012). However, investigation pertaining SI has been comparatively overlooked. In recent years, the risk associated with previous history of SI or any kind of STB - encompassing both SI and SA - has attracted interest in defined population subsets, such as adolescent and pediatric individuals (Villar et al., 2018)(Duarte et al., 2019), depression (Liu et al., 2016) or bordeline personality disorder (Rodante 
et al., 2019), but remains ill-explored in the general population. Only a few studies have dealt with the assessment of predictive factors for recurrence of any type of STB, including SI and SA (Hayashi et al., 2012), or specifically SI recurrence (Dugas et al., 2015)(de Beurs et al., 2019)(Kivelä et al., 2019).

Evidence from these and other studies (Statham et al., 1998) indicates that the risk of STB is determined by an interaction between genetic and environmental factors. Issues associated with disadvantage in health, social or economic domains (e.g. being unable to work or interpersonal conflicts) are more common among suicide re-attempters (Burón et al., 2016). Other contributory factors seemingly associated with suicide and SA recurrence are childhood history of abuse (Yip et al., 2011), sociodemographic factors such as age (Fridell et al., 1996) and gender (Fedyszyn et al., 2016)(Monnin et al., 2012), family history of suicide (Liu et al., 2017), medical comorbidities (Kawahara et al., 2017), psychiatric diseases (Arsenault-Lapierre et al., 2004), psychiatric hospitalization (Gunnell et al., 2008)(Qin and Nordentoft, 2005)(Fedyszyn et al., 2016), and history (and characteristics) of previous attempts (Beautrais, 2004)(Irigoyen et al., 2019)(Bostwick et al., 2016).

However, long and short-term studies of potential predictors for SA have yielded in many cases inconclusive results and none of the explanatory proposed models are fully reliable (Irigoyen et al., 2019). Therefore, determining the suicide risk of a given individual may be hard. An adequate classification of predisposition for STB, considering SA and SI as a whole, as well as each type separately, seems critical for secondary prevention, and may be useful in the implementation of preventive strategies at specialized mental health programs (Oquendo et al., 2008).

The present study was conceived as a pilot exploration of STB risk prior to the establishment of a multidisciplinary intensive suicide management program at the University Hospital of Marqués de Valdecilla (Cantabria, Spain). Specifically, its objective is to identify potential predictors for repeated STB, including SA and SI, within one year after presentation of an episode of STB at the Hospital Emergency Department; and to investigate the timing of repeated STB (in general), SA and SI. We also aim to determine which aspects are more specifically related to SA or SI recurrence.

\section{Methods}

\subsection{Subjects and study setting}


For this study, we included all patients presenting at the Emergency Department with an episode of STB, henceforth referred to as the index episode, during a period of four months (from March to June 2015) at University Hospital Marqués de Valdecilla, Cantabria, Spain. This hospital is the only medical institution with 24-hour Psychiatric Emergency Services in Cantabria, covering a catchment area of 550,000 inhabitants. Data were collected by the psychiatrists who were on duty during this period. STB included both attempt and ideation. Patients who denied any suicidal intent in their behavior were excluded. Conforming to international standards for research ethics, this study was approved by the local institutional review board.

\subsection{Study design}

The purpose of this prospective exploratory study was to determine the sociodemographic and clinical key factors for STB and their influence on STB (SI and/or SA) recurrence. Within the three months leading to the start of data collection, several informative seminars to all psychiatrists who worked at Emergencies were thoroughly carried out to guarantee the inclusion of all attended patients and all variables of interest.

\subsection{Predictor variables and follow-up}

At the index episode, the following sociodemographic information was collected from patients and medical records: gender, age, work status (1. employed/student; 2. unemployed/pensioner/retired), marital status (1. single/separated or divorced/widower; 2. married/in union) and sociofamiliar support (1. familiar/social support; 2. no support). In addition, the following personal and family history information was reported by patients or close relatives and recorded from medical records: family history of suicide, previous suicide tentative and number, history of physical and/or sexual abuse, somatic pathologies, psychiatric diseases and previous contact with mental health community units.

During the clinical exploration at the index episode, it was assessed if patient had depressive mood, had loss of rational thinking, or had an organised suicide plan. When, according to previous information and medical judgment, a psychiatric condition was present, the diagnosis was made through the psychopathological exploration following DSM-5 criteria. Clinical decision about destination after discharge was registered; for the present investigation, patients were 
dichotomized into admitted to the psychiatric ward and not admitted (including discharge to home and follow-up by general practitioner and attendance at mental health outpatient units). Estimation of suicide risk, calculated thorough the SAD Persons Scale (Patterson et al., 1983), was also recorded for this study.

After 12 months of follow-up, medical records of each included patient were screened by three psychiatrists (co-authors MPH, RMB and ELG). They examined whether the patient had returned to Emergencies for psychiatric assistance in relation to any instance of STB, sought psychiatric assistance for problems other than STB, and whether they had been in contact with mental health outpatient units during the follow-up.

\subsection{Definition of recurrence}

A patient was considered to have recurred if $s /$ he returned at least once to the Hospital Emergency Department due to SI or SA, within a year of follow-up after the index episode of STB. For individuals with multiple recurrences, only the first of them was analyzed.

Our research aimed to identify specific predictors of recurrence for each type of STB (namely SI and SA). Consequently, three classes of recurring events were considered: 1) STB-R: first recurrence of any type of STB (pooling SI and SA), 2) SA-R: first follow-up SA specifically and 3) SIR: first follow-up SI specifically.

\subsection{Statistical analysis}

For each event (STB-R, SA-R and SI-R), a dichotomous variable was created indicating whether or not a patient experienced a recurrence during the year of follow-up. All data were analyzed using IBM SPSS Statistics version 24 (IBM SPSS Statistics for Windows, Version 24.0. Armonk, NY: IBM Corp).

Considering each event separately, the comparison between characteristics of recurrent and nonrecurrent patients was first assessed by a univariate analysis using Pearson Chi-square tests for categorical variables, and one-way analyses of variance (ANOVAs) for continuous variables. Multivariate survival analyses using Multiple Cox regression were performed to assess the relative contribution of each potential predictor for the risk of STB-R, SA-R and SI-R during the 365-day 
follow-up. Recurrence (analysed separately for each outcome) was used as dependent variable. The following variables were explored as potential predictors: 1. Sociodemographic variables (age, gender, sociofamiliar support, marital status, employment); 2 . Family history of completed suicide; 3. Medical history (any somatic diseases, any psychiatric diseases, history of trauma or abuse, substance use including alcohol); 4. Previous SA and characteristics of the index event (number of attempts before the index episode, whether index episode consisted on SI or SA, planning of the index episode, hospital admission required at index); 5. Psychopathological exploration at the index episode (rational thinking, depressive mood); 6. Follow-up characteristics (contact with mental health outpatient units during the follow-up, visit to the Hospital Emergency Department for psychiatric reasons different than STB). SAD Person global score was not included as predictor because all of the individual items contributing to the score were included independently as covariates in the multivariate model. For the analysis with SI-R as outcome, the full model did not reach convergence (likely in relation to the small number of events, $n=10$ ). Consequently, a slightly different model was run after removal of three potential predictors, namely family history of completed suicide, hospital admission at index and contact with mental health outpatient units during follow-up.

Kaplan-Meier survival curves and Mantel-Cox log-rank test were used to analyze the time elapsed until recurrence. Patients who did not experience a recurrence of any STB (in STB-R model), SA (SA$\mathrm{R}$ model) or SI (SI-R model) were categorized as censored observations at the end of the follow-up.

The aforementioned survival models were performed on the entire sample. Therefore, regarding the separate outcomes SA-R and SI-R, patients with no recurrence on the outcome of interest might still have a recurrence of different type. For example, the model on SI-R compares patients who recurred with SI with all other patients, encompassing those who presented SA and those with no STB during the 1-year follow-up. In order to assess risk of each specific type of STB with a more homogeneous comparison group, we performed a set of secondary analyses, by running the SA-R and SI-R survival models on a subset of the sample, namely those who either recurred with the event of interest or did not recur with any STB at all.

\section{Results}

\subsection{Description of study cohort}


During the four-month recruitment phase of this pilot study, 109 patients (35 males, 32.1\%) were evaluated by psychiatrists in the Emergency Department for STB. One patient died during the follow-up for medical reasons and dropped out of the study. Therefore, 108 subjects were traced and considered to be at risk of recurrence of STB during one year of follow-up after the index episode. Out of the 108, two patients died by suicide after 84 and 195 days of the index episode of STB.

Baseline sociodemographic and clinical characteristics of the sample are shown in Table 1. A psychiatric diagnosis was specified in $75 \%(n=81)$ of all STB. At the index episode, forty-seven patients (43.5\%) presented to Emergencies with SI whereas sixty-one patients (56.5\%) presented with SA. With respect to methods of SA, drug overdose was the most prevalent, used by $72.1 \%$ of patients with STB at baseline $(n=44)$; other suicide methods were: cutting $(n=8 ; 13.1 \%)$, hanging $(n=4 ; 6.6 \%)$, gas asphyxiation $(n=1 ; 1.6 \%)$; self-defenestration $(n=1 ; 1.6 \%)$; and others $(n=3$; 4.92.8\%). Almost $50 \%$ of participants $(n=53)$ had already attempted suicide at least once before the index episode.

There were not significant gender differences between baseline variables, with exception of SAD Person Score ( $F=12.06 ; p=0.001)$, where males obtained a significant higher score (3.24) compared with women (2.35). However, this difference of 0.89 approximates the additional point that the scale gives to the male gender with respect to female for estimating the suicide risk.

Thirty-four patients (31.5\%) returned to Emergencies at least once for STB recurrence during the first year of follow-up. Out of those 34 recurring patients, 25 (73.5\%) attempted suicide at least once (see Figure 1).

\subsection{Exploring STB-R}

Thirty-four patients (31.5\%) experienced at least one STB recurrence over the one-year follow-up, comprising both suicidal ideation and suicide attempts. In the univariate analysis, STB recurrence rates were associated to a greater number of previous attempts $(F=6.47 ; d f=1 ; p=0.012)$; contact with mental health outpatient units during the year of follow-up $\left(X^{2}=10.67 ; d f=1 ; p=0.001\right)$; and visit to the Emergency Department for psychiatric reasons different than STB during the year of follow-up $\left(X^{2}=22.00 ; d f=1 ; p \leq 0.001\right)$. 
Cox proportional hazard regression confirmed the results obtained in the univariate analysis, showing that an increased number of previous SA ( $H R=1.316 ; 95 \% \mathrm{Cl} 1.046-1.657 ; p=0.019)$, being in contact with mental health outpatient units during follow-up $(\mathrm{HR}=12.783 ; 95 \% \mathrm{Cl} 1.543-$ 105.934; $p=0.018$ ) and emergency visits for psychiatric reasons different than STB (HR=6.495; 95\% Cl 2.967 - 14.218; $p<0.001$ ) were significant predictors for STB-R (Table 2).

The average survival time for STB-R during one year of follow-up was 287.9 days $(95 \% \mathrm{Cl}=263.8$ 312.1), computed on all patients (with or without recurrence) until STB-R event or end of followup (Figure 2); the median time (computed on those patients who had a recurrence) was 97 days (95\% Cl= 37 - 157). The survival curve showed $70.6 \%(n=24)$ of STB-R occurred during the first six months. It is worth noting that survival distribution of STB-R was significantly different between patients who had committed more than two previous SA and patients with two or less previous attempts (median time of survival: 60 vs. 97 days, Mantel-Cox log rank test: $X^{2}=10.71, d f=1$, $p=0.001$ ); also the time difference was considerable between patients in contact and patients without contact with mental health outpatients units (97 vs. 195 days; log rank test: $X^{2}=9.551$; $d f=1 ; p=0.002) ;$ and in the same vein, between patients that visited and did not visit the Hospital Emergency Department for psychiatric reasons different than STB attention (60 vs 123 days: log rank test: $\left.X^{2}=28.669, d f=1, p<0.001\right)$. Figure 3 shows the comparison between time of STB- $R$ in the whole sample, according to significant predictors, during the year of follow-up.

\subsection{Exploring $S A-R$}

After the index episode of STB, 25 patients (23.1\%) were attended at Emergencies for at least one SA within one year of follow-up. Univariate analysis indicated that a greater number of previous SA $(F=6.52 ; d f=1 ; p=0.012)$; requiring hospital admission based on index episode characteristics $\left(X^{2}=6.59 ; d f=1 ; p=0.017\right)$; having contact with mental health outpatients units during the follow-up $\left(X^{2}=6.25 ; d f=1 ; p=0.012\right) ;$ and visiting Emergencies for psychiatric reasons different than STB during the follow-up $\left(X^{2}=5.92 ; \mathrm{df}=1 ; \mathrm{p}=0.023\right)$ were significantly associated with $\mathrm{SA}-\mathrm{R}$.

In multivariate Cox regression analyses, the following factors were significant predictors for SA-R: greater number of previous SA ( $\mathrm{HR}=1.314 ; 95 \% \mathrm{Cl}=1.032-1.673 ; \mathrm{p}=0.027)$; being hospitalized because of the index episode $(\mathrm{HR}=4.467 ; 95 \% \mathrm{Cl}=1.572$ - 12.692; $\mathrm{p}=0.005)$; having contact with mental health outpatient units during follow-up ( $\mathrm{HR}=11.850 ; 95 \% \mathrm{Cl}=1.317-106.663 ; \mathrm{p}=0.027)$ and visiting to Emergencies for psychiatric causes different than STB ( $\mathrm{HR}=3.305$; $95 \% \mathrm{Cl}=1.375-7.946$; 
$\mathrm{p}=0.008$ ). In addition, having no active employment or occupation (i.e. being unemployed or in retirement) was a borderline significant predictor for $\mathrm{SA}-\mathrm{R}(\mathrm{HR}=3.600 ; 95 \& \mathrm{Cl}=0.998-12.989$; $\mathrm{p}=0.050$ ) (Table 3).

The mean survival time during one-year follow-up was 310.3 days ( $95 \% \mathrm{Cl}=288.9-331.7$ ) (Figure 2), with a median time (for those who recurred) of 97 days ( $95 \% \mathrm{Cl}=28.46-165.55)$; $68 \%$ of reattempts took place during the first six months $(n=17)$. Survival time was significantly different between those patients with and without any previous SA in their lifetime (median time until event 64 vs 114 days; log rank test: $X^{2}=6.98, d f=1, p=0.008$ ); the time for $S A-R$ was also dissimilar between those individuals who were hospitalized at the index episode and those who were not hospitalized (64 vs. 106 days; log rank test: $X^{2}=6.83, d f=1, p=0.009$ ). In addition, it differed between those patients who had visited and those who had not visited the Emergency Department for psychiatric reasons other than STB ( 60 vs. 123 days; log rank test: $X^{2}=6.85, d f=1, p=0.009$ ); and also between those with and without contact with mental health units during follow-up (84 vs 195 days; log rank test: $\left.X^{2}=5.81, d f=1, p=0.016\right)$. Figure 4 shows the comparison of time to $S A-R$ in whole sample during the follow-up, according to significant predictive factors.

\subsubsection{Subset analysis: $S A-R$ compared to no recurrence of any type}

In order to directly compare SA-R with lack of any STB recurrence, those participants who recurred with SI were removed from the no-event group and the same Cox regression model was run for SA-R on the remaining cases. The sample size for this model was $n=98$, including 24 cases of SA-R and 74 patients with no STB recurrence of any kind.

Results were similar than those for the entire sample, with significantly higher risk for SA-R among those with no active employment or occupation ( $\mathrm{HR}=4.283 ; 95 \% \mathrm{Cl} 1.017-18.034 ; \mathrm{p}=0.047)$, greater number of previous suicide attempts before the index episode $(\mathrm{HR}=1.435 ; 95 \% \mathrm{Cl} 1.061$ 1.939; $p=0.019)$, hospital admission required at the index episode $(H R=4.074 ; 95 \% \mathrm{Cl} 1.302$ 12.745; $p=0.016)$, contact with mental health outpatient units during follow-up ( $H R=12.025 ; 95 \%$ $\mathrm{Cl} 1.287$ - 112.351; $p=0.029$ ) and visits to the Emergency Department for psychiatric reasons other than STB $(H R=4.456 ; 95 \% \mathrm{Cl} 1.794-11.068 ; p=0.001)$.

\subsection{Exploring SI-R}


Ten patients (9.3\%) returned to the Emergency Department reporting SI within one-year followup after the index episode, including one patient who also recurred with SA on a later date. According to univariate comparisons, the type of index event was significantly associated with SI$\mathrm{R}$, in that a greater proportion of those with $\mathrm{SI}$ at index (compared to index $\mathrm{SA}$ ) recurred with $\mathrm{SI}$ (17.0\% vs 3.3\%; $\left.X^{2}=5.97 ; d f=1 ; p=0.015\right)$. Likewise, visiting the Emergency Department during follow-up for psychiatric reasons other than STB was associated to SI-R $\left(X^{2}=20.23 ; d f=1 ; p<0.001\right)$. Chi-squared comparison regarding contact with mental health outpatient units during follow-up suggested a non-significant trend $(p=0.076)$ : indeed, all patients with SI-R had contact with mental health units.

Survival analysis by multivariate Cox regression supported the results in the univariate comparisons but also yielded other findings. There were three significant predictors for SI-R, namely lack of comorbid depression at index (HR for depression was 0.019; 95\% Cl= $0.001-0.681$; $\mathrm{p}=0.030$ ), type of index event (risk was 15.625 times greater if index had also been $\mathrm{SI}$; in other words, HR for SA was 0.064; $95 \% \mathrm{Cl} 0.006-0.643 ; \mathrm{p}=0.020$ ) and Emergency visits for psychiatric reasons different than STB during follow-up ( $\mathrm{HR}=71.059 ; 95 \% \mathrm{Cl}=4.637$ - 1089.044; $\mathrm{p}=0.002)$. Note that there were three potential predictors that could not be included in the model for lack of convergence (family history of suicide, hospital admission, contact with mental health units during follow-up) although none of them were associated to SI-R in the univariate comparisons. See Table 4 for detailed model results.

The mean survival time was 339.3 days $(95 \% \mathrm{Cl}=323.5$ - 355.1) (Figure 2); the median time for those who experienced SI-R was 35 days $(95 \% \mathrm{Cl}=0.00$ - 149.66), with $80 \%$ cases recurring within the first six months. There was a significant difference in time to SI-R between patients with SI (compared to $S A$ ) at index (log rank test: $\left.X^{2}=5.883, d f=1, p=0.015\right)$, and between patients who returned to the Emergency Department for psychiatric reasons other than STB during follow-up, and those who did not (log rank test: $\left.\mathrm{X}^{2}=21.797, \mathrm{df}=1, \mathrm{p}<0.001\right)$. The survival Kaplan Meier curves across levels of these significant predictors are presented in Figure $\mathbf{5}$.

\subsubsection{Subset analysis: SI-R compared to no recurrence of any type}

Patients whose first recurrence was with suicide attempt were subsequently removed, and the multivariate Cox survival model was re-run for contrasting SI-R with absence of any recurring STB. The sample for this model consisted on 84 patients, out of which 10 had SI-R and 74 had no 
recurrence of any kind within the 12-month follow-up. For this subset there were three significant predictors for $\mathrm{SI}-\mathrm{R}$, namely older age $(\mathrm{HR}=1.152 ; 95 \% \mathrm{Cl}=1.016-1.306 ; \mathrm{p}=0.028)$, use of alcohol and other toxics ( $\mathrm{HR}=130.947 ; 95 \% \mathrm{Cl}=1.272-13691.711)$ and visit to Emergencies during followup for psychiatric reasons other than STB (HR= 2063.999; 95\% $\mathrm{Cl}=18.252$ - 233400.626; $\mathrm{p}=0.002)$.

\section{Discussion}

In our exploratory cohort, out of the 109 patients recruited at the index episode, two individuals (1.8\%) died by suicide during the year of follow-up. These results are in agreement with classical reports, showing rates of $0.5-2 \%$ after 1 year of self-harm (Owens et al., 2002). The gender rate of STB was $68 \%$ females and $32 \%$ males, being gender a commonly found factor for non-fatal STB (Borges et al., 2010) with rates 50\% higher in women compared with men (Schmidtke et al., 1996)(Hawton and Harriss, 2008).

Our results show frequencies of 31.5\%, 23.1\%, and 9.3\% for recurrence of STB, SA, and SI within 1 year, respectively. The rates of suicide re-attempts lie in the high end of the spectrum reported in some previous investigations, with recurrences between $15-25 \%$ of deliberated self-harm after one year of the previous episode (Bancroft and Marsack, 1977) (Owens et al., 2002); other studies with comparable follow-up periods reported similar results (Bilén et al., 2011), but smaller rates of SA relapse among adults over 60 years (Murphy et al., 2012). With regard to any STB, including SI and SA, a two-year prospective study found recurrences of $67 \%$ (Hayashi et al., 2012). In case of SI, two longitudinal studies reported $19.5 \%$ and $32 \%$ recurrences after three and four years of follow-up (Liu et al., 2016)(Dugas et al., 2015). Considering the time of recurrence, we observed that the risk for all event types was particularly high in the first six months with around $70 \%$ of one-year recurrences (80\% for SI), consistent with past research (Cooper et al., 2005)(Bhaskaran et al., 2014)(Irigoyen et al., 2019). These results highlight the importance of early interventions for suicide prevention during at least six months after an episode of STB.

A common risk factor for one-year recurrence of STB in general, SA and SI was seeking for emergency help for psychiatric problems different than STB during the follow-up. Contact with

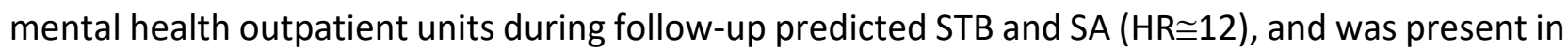
all patients who recurred with SI (although it was not significantly associated in univariate analysis 
and could not be included in the Cox survival model for lack of convergence). Interestingly, different patterns of predictive factors for SA and SI were also found. Specific predictors for SA recurrence were: 1 ) previous history and number of SA (also a predictor for STB in general), with risk multiplying by 1.3 for each additional SA episode; 2 ) admission to psychiatric hospitalization at index, which led to more than six-fold risk for reattempts during the year of follow-up. Besides, lack of active employment was a nearly significant predictor for SA recurrence (HR=3.600; $p=0.05)$. Conversely, specific predictors for SI recurrence were SI at index (conveying more than fifteen-fold risk compared to index $\mathrm{SA}$ ) and lack of depression at index.

Perhaps the most well-documented indicator of future attempted or completed suicide is a history of SA (Neeleman, 2001)(Bernal et al., 2007) (Suokas et al., 2001)(World Health Organization, 2014)(Nock et al., 2008). Our study found that those patients with previous SA had a shorter delay between the index episode and the recurrence of STB and SA. A larger number of previous SA may indicate ongoing or chronic psychosocial problems, and may be associated with continuing risk of suicide (Zahl and Hawton, 2004). Therefore, a detailed enquiry about previous SA history is important in risk assessment including those episodes that have not resulted in presentation at the Emergency Department - and also including deliberate self-harm episodes that are not clearly suicidal, since intent is often ambivalent or difficult to assess, and non-suicidal self-harm has high comorbidity and is a known predictor for SA (World Health Organization, 2014)(Posner, 2007). In this line, our findings showed a shorter delay of STB repetition related with certain characteristics of the follow-up (such as contact with mental health services and with Psychiatric Emergencies for issues other than STB), probably indicating a help-seek behavior related with suicidality (Chien et al., 2013). Specifically, $85 \%$ of the STB recurrent patients in our sample had a diagnosis of psychiatric disease, whereas $97 \%$ of them were in contact with mental health outpatient units during the year of follow-up. This difference may be partially explained by the well-known stressdiathesis model in which the risk for STB is determined not merely by a psychiatric illness or an adaptive problem (the stressor) but also by a diathesis (personality and tendency to experience suicidal ideation) (Mann et al., 1999). In this regard, lack of active employment may be both a reflection of such vulnerable diathesis and a key stressor in some patients, as suggested by our results (Hawton and van Heeringen, 2009)(Platt and Hawton, 2008).

Moreover, while for the whole sample $18.5 \%$ patients required hospital admission at the index episode, such percent was significantly higher for those individuals who would have at least one SA during the follow-up (36\%). Clinical decision leading to hospital admission at index was revealed 
in our study as one of the most important indicators of future SA. These findings concur with previous reports showing that suicide and intentional self-harm rates were higher during the year after discharge from psychiatric ward (Ho, 2003)(Gunnell et al., 2008). This may suggest that emergency psychiatrist doctors are able to provide an accurate high-level summary measure for targeting the most high-risk individuals and referring them to more intensive forms of management (Kapur et al., 2013). Previous findings validate the importance of clinical judgement in assessing suicide risk (Barzilay et al., 2019)(Wang et al., 2016). Therefore, a rigorous clinical exploration of characteristics of previous and current SA, but also SI, may help to screen subjects on risk of recurrence at the first presentation at Emergency Department (Ayuso-Mateos et al., 2012). However, although the clinical decision of admission probably helps patients during the acute crisis, a closer monitorization after discharge seems necessary.

Specialized clinical programs for suicide prevention could offer a more intensive and specific care for crisis intervention and during the short-term follow-up compared with the routine treatment at mental health outpatient units, achieving a higher treatment compliance. However, a multidisciplinary approach with coordination of all involved medical and social devices (such as occupation therapists and social workers) is needed to ensure a medium and long-term follow-up. The maintenance of an structured follow-up for suicide attempters may reduce repetition of the SA and should be included in any suicide prevention strategy (Zalsman et al., 2016)(Turecki and Brent, 2016).

Contrary to SA, hospital admission or number of previous SA episodes were not predictors for SI recurrence. Although these differences should be carefully evaluated because of the small sample size, a likely explanation for discrepancies between recurrences of SA and SI may be that STB is a "pathway to suicide" (Maris et al., 2000), from ideation to attempt and to completed suicide, wherein patients with SI may be at a stage of lower risk of suicide completion than those with SA. However, although some studies consider that individuals with $\mathrm{SI}$ are a separate group of other suicidal individuals (and this may be somewhat supported in our results by the fact that index $\mathrm{SI}$ is predictor of follow-up SI), they constitute a clinical priority because most of suicide completers had suicidal thoughts prior to their acts (McAuliffe, 2002), and 60\% of transitions from ideation to attempt occur within the first year after ideation onset (Nock et al., 2008).

Another significant predictor for SI recurrence was lack of comorbid depression at index. This may be surprising, given that depression is a well-established risk factor for all forms of STB (Nock et 
al., 2008), but the small number of SI events, a possibility of self-reporting bias and the fact that the no-event group in the survival model for ideation includes SA events should be considered. Indeed, lack of depression is no longer a predictor when patients with SA recurrence are removed from the model, although this post-hoc result must be taken with caution.

There are some limitations to our study. The most important is that our exploratory cohort is small and therefore subgroup analyses based on potential key variables such as gender, age, specific diagnosis or methods of SA were not possible. However, results of our univariate analyses did not find any significant effect of those variables, and gender and age were included as covariates in the Cox regression analyses, finding no significant associations with STB or SA differences. For the same reason, the number of SI recurrences was particularly small $(n=10)$ and the full survival model applied for STB and SA could not be run for SI due to lack of convergence; nevertheless, the three variables that had to be removed from the SI model were not significantly associated in the exploratory univariate analyses. Secondly, a number of recurrences may not result in presentation to hospital and therefore may have not been taken into account; nevertheless, the fact that the University Hospital Marqués de Valdecilla is the only with 24-hour Emergency Psychiatric Department in the county of Cantabria ensures the inclusion of all STB (SA and SI) that required urgent assistance. Thirdly, some potentially relevant variables were not routinely collected at Emergency Department such as impulsivity, sleep disturbances, global functioning or treatment compliance because interventions at Emergencies limit the administration of long assessment protocols or structured interviews. However, these variables were found to be relevant risk factors for STB recurrence in the literature, and therefore, should be taken into account in future study designs. On the other hand, some strengths worth considering in this study are its prospective cohort design and the distinction between recurrences of STB in general, SA and SI at Emergencies.

In conclusion, further research is needed to target potential suicide predictors through a careful exploration of suicide attempt and ideation at the Emergency Department. Other factors not usually explored at Emergencies such as global functioning or treatment compliance may be also important and should be borne in mind during the follow-up clinical assessment. Moreover, welldesigned studies exploring the effect of preventive interventions or different types of treatment provided during the hospitalization or the intensive follow-up should be carried out to determine its influence between recurrent and non-recurrent patients. Potentially key preventive strategies may include the provision of adequate support to patients discharged from psychiatric inpatient 
care who survived previous STB thorough a multidisciplinary follow-up, considering medical and psychiatric diseases, but also concurrent psychosocial or adaptive problems.

\section{Author contributions}

P.S.P. was responsible for formal analysis of the data, decisions on methodology and writing of the article. M.P.H., R.M.B. and E.L.G. were responsible for data curation. M.S.P. was responsible for decisions on methodology, analysis, writing and revision of the article. J.A.S. was responsible for the project administration. A.S.D. was responsible for conceptualization of the study, decisions of methodology and supervision. P.S.P and M.S.P have equally contributed to this work.

\section{Conflict of interest}

The authors do not report any conflict of interest.

\section{Funding}

This research did not receive any specific grant from funding agencies in the public, commercial, or other sectors.

\section{Acknowledgements}

The authors would like to thank the doctors on duty at the Emergency department who were responsible for the initial assessment of the participants in this study.

\section{References}

American Psychiatric Association, 2013. Diagnostic and Statistical Manual of Mental Disorders (5th ed.). Am. Psychiatr. Publ.

American Psychiatric Association, 2003. Practice guideline for the assessment and treatment of patients with suicidal behaviors. Am. J. Psychiatry 160, 1-60.

Arsenault-Lapierre, G., Kim, C., Turecki, G., 2004. Psychiatric diagnoses in 3275 suicides: a metaanalysis. BMC Psychiatry 4, 37. https://doi.org/10.1186/1471-244X-4-37

Ayuso-Mateos, J.L., Baca-García, E., Bobes, J., Giner, J., Giner, L., Pérez, V., Sáiz, P.A., Saiz Ruiz, J., 2012. Recommendations for the prevention and management of suicidal behaviour. Rev. Psiquiatr. Salud Ment. 5, 8-23. https://doi.org/10.1016/j.rpsm.2012.01.001

Bancroft, J., Marsack, P., 1977. The repetitiveness of self-poisoning and self-injury. Br. J. Psychiatry 131, 394-9. https://doi.org/10.1192/bjp.131.4.394

Barzilay, S., Yaseen, Z.S., Hawes, M., Kopeykina, I., Ardalan, F., Rosenfield, P., Murrough, J., Galynker, I., 2019. Determinants and Predictive Value of Clinician Assessment of Short-Term Suicide Risk. Suicide Life-Threatening Behav. 49, 614-626. 
https://doi.org/10.1111/sltb.12462

Beautrais, A.L., 2004. Further Suicidal Behavior Among Medically Serious Suicide Attempters. Suicide Life-Threatening Behav. 34, 1-11. https://doi.org/10.1521/suli.34.1.1.27772

Bernal, M., Haro, J.M., Bernert, S., Brugha, T., de Graaf, R., Bruffaerts, R., Lépine, J.P., de Girolamo, G., Vilagut, G., Gasquet, I., Torres, J. V., Kovess, V., Heider, D., Neeleman, J., Kessler, R., Alonso, J., 2007. Risk factors for suicidality in Europe: Results from the ESEMED study. J. Affect. Disord. 101, 27-34. https://doi.org/10.1016/j.jad.2006.09.018

Bhaskaran, J., Wang, Y., Roos, L., Sareen, J., Skakum, K., Bolton, J.M., 2014. Method of suicide attempt and reaction to survival as predictors of repeat suicide attempts: a longitudinal analysis. J. Clin. Psychiatry 75, e802-8. https://doi.org/10.4088/JCP.13m08879

Bilén, K., Ottosson, C., Castrén, M., Ponzer, S., Ursing, C., Ranta, P., Ekdahl, K., Pettersson, H., 2011. Deliberate self-harm patients in the emergency department: Factors associated with repeated self-harm among 1524 patients. Emerg. Med. J. 28, 1019-1025. https://doi.org/10.1136/emj.2010.102616

Borges, G., Nock, M.K., Abad, J.M.H., Hwang, I., Sampson, N.A., Alonso, J., Andrade, L.H., Angermeyer, M.C., Beautrais, A., Bromet, E., Bruffaerts, R., De Girolamo, G., Florescu, S., Gureje, O., Hu, C., Karam, E.G., Kovess-Masfety, V., Lee, S., Levinson, D., Medina-Mora, M.E., Ormel, J., Posada-Villa, J., Sagar, R., Tomov, T., Uda, H., Williams, D.R., Kessler, R.C., 2010. Twelve-month prevalence of and risk factors for suicide attempts in the world health organization world mental health surveys. J. Clin. Psychiatry 71, 1617-1628. https://doi.org/10.4088/JCP.08m04967blu

Bostwick, J.M., Pabbati, C., Geske, J.R., McKean, A.J., 2016. Suicide attempt as a risk factor for completed suicide: Even more lethal than we knew. Am. J. Psychiatry 173, 1094-1100. https://doi.org/10.1176/appi.ajp.2016.15070854

Burón, P., Jimenez-Trevino, L., Saiz, P.A., García-Portilla, M.P., Corcoran, P., Carli, V., Fekete, S., Hadlaczky, G., Hegerl, U., Michel, K., Sarchiapone, M., Temnik, S., Värnick, A., Verbanck, P., Wasserman, D., Schmidtke, A., Bobes, J., 2016. Reasons for Attempted Suicide in Europe: Prevalence, Associated Factors, and Risk of Repetition. Arch. Suicide Res. 20, 45-58. https://doi.org/10.1080/13811118.2015.1004481

Cavanagh, J.T.O., Carson, A.J., Sharpe, M., Lawrie, S.M., 2003. Psychological autopsy studies of suicide: A systematic review. Psychol. Med. https://doi.org/10.1017/S0033291702006943

Chien, W.-C., Lai, C.-H., Chung, C.-H., Pai, L., Chang, W.-T., 2013. A nation-wide evidence-based data analysis of repeated suicide attempts. Crisis 34, 22-31. https://doi.org/10.1027/02275910/a000157

Cooper, J., Kapur, N., Webb, R., Lawlor, M., Guthrie, E., Mackway-Jones, K., Appleby, L., 2005. Suicide after deliberate self-harm: A 4-year cohort study. Am. J. Psychiatry 162, 297-303. https://doi.org/10.1176/appi.ajp.162.2.297

de Beurs, D., ten Have, M., Cuijpers, P., de Graaf, R., 2019. The longitudinal association between lifetime mental disorders and first onset or recurrent suicide ideation. BMC Psychiatry 19, 345. https://doi.org/10.1186/s12888-019-2328-8

Duarte, T.A., Paulino, S., Almeida, C., Gomes, H.S., Santos, N., Gouveia-Pereira, M., 2019. Selfharm as a predisposition for suicide attempts: A study of adolescents' deliberate self-harm, suicidal ideation, and suicide attempts. Psychiatry Res.

https://doi.org/10.1016/j.psychres.2019.112553

Dugas, E.N., Low, N.C., O'Loughlin, E.K., O'Loughlin, J.L., 2015. Recurrent suicidal ideation in young adults. Can. J. Public Health 106, e303-7. https://doi.org/10.17269/cjph.106.4774

Fedyszyn, I.E., Erlangsen, A., Hjorthoj, C., Madsen, T., Nordentoft, M., 2016. Repeated suicide attempts and suicide among individuals with a first emergency department contact for attempted suicide: A prospective, nationwide, danish register-based study. J. Clin. Psychiatry 77, 832-840. https://doi.org/10.4088/JCP.15m09793

Fridell, E.J., Öjehagen, A., Träskman-Bendz, I., 1996. A 5-year follow-up study of suicide attempts. 
Acta Psychiatr. Scand. 93, 151-157. https://doi.org/10.1111/j.1600-0447.1996.tb10622.x

Gallego, J.A., Rachamallu, V., Yuen, E.Y., Fink, S., Duque, L.M., Kane, J.M., 2015. Predictors of suicide attempts in 3.322 patients with affective disorders and schizophrenia spectrum disorders. Psychiatry Res. 228, 791-796. https://doi.org/10.1016/j.psychres.2015.05.024

Gunnell, D., Hawton, K., Ho, D., Evans, J., O’Connor, S., Potokar, J., Donovan, J., Kapur, N., 2008. Hospital admissions for self harm after discharge from psychiatric inpatient care: Cohort study. BMJ 337, 1331-1334. https://doi.org/10.1136/bmj.a2278

Hawton, K., Harriss, L., 2008. The changing gender ratio in occurrence of deliberate self-harm across the lifecycle. Crisis 29, 4-10. https://doi.org/10.1027/0227-5910.29.1.4

Hawton, K., van Heeringen, K., 2009. Suicide. Lancet. https://doi.org/10.1016/S01406736(09)60372-X

Hayashi, N., Igarashi, M., Imai, A., Yoshizawa, Y., Utsumi, K., Ishikawa, Y., Tokunaga, T., Ishimoto, K., Harima, H., Tatebayashi, Y., Kumagai, N., Nozu, M., Ishii, H., Okazaki, Y., 2012. Posthospitalization course and predictive signs of suicidal behavior of suicidal patients admitted to a psychiatric hospital: a 2-year prospective follow-up study. BMC Psychiatry 12, 186. https://doi.org/10.1186/1471-244X-12-186

Ho, T.-P., 2003. The suicide risk of discharged psychiatric patients. J. Clin. Psychiatry 64, 702-7. https://doi.org/10.4088/jcp.v64n0613

Irigoyen, M., Porras-Segovia, A., Galván, L., Puigdevall, M., Giner, L., De Leon, S., Baca-García, E., 2019. Predictors of re-attempt in a cohort of suicide attempters: A survival analysis. J. Affect. Disord. 247, 20-28. https://doi.org/10.1016/j.jad.2018.12.050

Kapur, N., Steeg, S., Webb, R., Haigh, M., Bergen, H., Hawton, K., Ness, J., Waters, K., Cooper, J., 2013. Does Clinical Management Improve Outcomes following Self-Harm? Results from the Multicentre Study of Self-Harm in England. PLoS One 8. https://doi.org/10.1371/journal.pone.0070434

Kawahara, Y.Y., Hashimoto, S., Harada, M., Sugiyama, D., Yamada, S., Kitada, M., Sakurai, T., Takahashi, T., Yamashita, K., Watanabe, K., Mimura, M., Fujisawa, D., 2017. Predictors of short-term repetition of self-harm among patients admitted to an emergency room following self-harm: A retrospective one-year cohort study. Psychiatry Res. 258, 421-426. https://doi.org/10.1016/j.psychres.2017.08.077

Kivelä, L., Krause-Utz, A., Mouthaan, J., Schoorl, M., de Kleine, R., Elzinga, B., Eikelenboom, M., Penninx, B.W., van der Does, W., Antypa, N., 2019. Longitudinal course of suicidal ideation and predictors of its persistence - A NESDA study. J. Affect. Disord. 257, 365-375. https://doi.org/10.1016/j.jad.2019.07.042

Liu, Y., Sareen, J., Bolton, J.M., Wang, J.L., 2016. Development and validation of a risk prediction algorithm for the recurrence of suicidal ideation among general population with low mood. J. Affect. Disord. 193, 11-7. https://doi.org/10.1016/j.jad.2015.12.072

Liu, Y., Zhang, J., Sun, L., 2017. Who are likely to attempt suicide again? A comparative study between the first and multiple timers. Compr. Psychiatry 78, 54-60. https://doi.org/10.1016/j.comppsych.2017.07.007

Mann, J.J., Waternaux, C., Haas, G.L., Malone, K.M., 1999. Toward a clinical model of suicidal behavior in psychiatric patients. Am. J. Psychiatry 156, 181-189. https://doi.org/10.1176/ajp.156.2.181

Maris, R., Berman, A., Silvermann, M., 2000. The theoretical component in suicidology. Comprehensive texbook of suicidology 26-61.

McAuliffe, C.M., 2002. Suicidal ideation as an articulation of intent: $A$ focus for suicide prevention? Arch. Suicide Res. 6, 325-338. https://doi.org/10.1080/13811110214524

Monnin, J., Thiemard, E., Vandel, P., Nicolier, M., Tio, G., Courtet, P., Bellivier, F., Sechter, D., Haffen, E., 2012. Sociodemographic and psychopathological risk factors in repeated suicide attempts: Gender differences in a prospective study. J. Affect. Disord. 136, 35-43. https://doi.org/10.1016/j.jad.2011.09.001 
Murphy, E., Kapur, N., Webb, R., Purandare, N., Hawton, K., Bergen, H., Waters, K., Cooper, J., 2012. Risk factors for repetition and suicide following self-harm in older adults: Multicentre cohort study. Br. J. Psychiatry 200, 399-404. https://doi.org/10.1192/bjp.bp.111.094177

Neeleman, J., 2001. A continuum of premature death. Meta-analysis of competing mortality in the psychosocially vulnerable. Int. J. Epidemiol. 30, 154-162.

https://doi.org/10.1093/ije/30.1.154

Nock, M.K., Borges, G., Bromet, E.J., Alonso, J., Angermeyer, M., Beautrais, A., Bruffaerts, R., Wai, T.C., De Girolamo, G., Gluzman, S., De Graaf, R., Gureje, O., Haro, J.M., Huang, Y., Karam, E., Kessler, R.C., Lepine, J.P., Levinson, D., Medina-Mora, M.E., Ono, Y., Posada-Villa, J.,

Williams, D., 2008. Cross-national prevalence and risk factors for suicidal ideation, plans and attempts. Br. J. Psychiatry 192, 98-105. https://doi.org/10.1192/bjp.bp.107.040113

Oquendo, M.A., Baca-García, E., Mann, J.J., Giner, J., 2008. Issues for DSM-V: suicidal behavior as a separate diagnosis on a separate axis. Am. J. Psychiatry 165, 1383-4.

https://doi.org/10.1176/appi.ajp.2008.08020281

Owens, D., Horrocks, J., House, A., 2002. Fatal and non-fatal repetition of self-harm. Systematic review. Br. J. Psychiatry. https://doi.org/10.1192/bjp.181.3.193

Patterson, W.M., Dohn, H.H., Bird, J., Patterson, G.A., 1983. Evaluation of suicidal patients: The SAD PERSONS scale. Psychosomatics 24, 343-345. https://doi.org/10.1016/S00333182(83)73213-5

Platt, S., Hawton, K., 2008. Suicidal Behaviour and the Labour Market, in: The International Handbook of Suicide and Attempted Suicide. John Wiley and Sons Ltd., West Sussex, England, pp. 309-384. https://doi.org/10.1002/9780470698976.ch20

Posner, K., 2007. Columbia Classification Algorithm of Suicide Assessment (C-CASA): Classification of Suicidal Events in the FDA's Pediatric Suicidal Risk Analysis of Antidepressants. Am. J. Psychiatry 164, 1035. https://doi.org/10.1176/appi.ajp.164.7.1035

Qin, P., Nordentoft, M., 2005. Suicide risk in relation to psychiatric hospitalization: Evidence based on longitudinal registers. Arch. Gen. Psychiatry 62, 427-432. https://doi.org/10.1001/archpsyc.62.4.427

Rodante, D.E., Grendas, L.N., Puppo, S., Vidjen, P., Portela, A., Rojas, S.M., Chiapella, L.C., Daray, F.M., 2019. Predictors of short- and long-term recurrence of suicidal behavior in borderline personality disorder. Acta Psychiatr. Scand. 140, 158-168. https://doi.org/10.1111/acps.13058

Ros, S., Arranz, F., 2015. Suicidal Behavior, in: Vallejo-Ruiloba, J. (Ed.), Introduction to Psychopathology and Psychiatry. Elsevier España, S.L.U, pp. e173-e198.

Schmidtke, A., 1997. Perspective: suicide in Europe. Suicide Life. Threat. Behav. 27, 127-36.

Schmidtke, A., Bille-Brahe, U., DeLeo, D., Kerkhof, A., Bjerke, T., Crepet, P., Haring, C., Hawton, K., Lönnqvist, J., Michel, K., Pommereau, X., Querejeta, I., Phillipe, I., Salander-Renberg, E., Temesváry, B., Wasserman, D., Fricke, S., Weinacker, B., Sampaio-Faria, J.G., 1996.

Attempted suicide in Europe: Rates, trends and sociodemographic characteristics of suicide attempters during the period 1989-1992. Results of the WHO/EURO Multicentre Study on Parasuicide. Acta Psychiatr. Scand. 93, 327-338. https://doi.org/10.1111/j.16000447.1996.tb10656.x

Skegg, K., 2005. Self-harm, in: Lancet. pp. 1471-1483. https://doi.org/10.1016/S01406736(05)67600-3

Statham, D.J., Heath, A.C., Madden, P.A., Bucholz, K.K., Bierut, L., Dinwiddie, S.H., Slutske, W.S., Dunne, M.P., Martin, N.G., 1998. Suicidal behaviour: an epidemiological and genetic study. Psychol. Med. 28, 839-55. https://doi.org/10.1017/s0033291798006916

Suokas, J., Suominen, K., Isometsaè, E., Ostamo, A., Loènnqvist, J., 2001. Long-term risk factors for suicide mortality after attempted suicide - Findings of a 14-year follow-up study. Acta Psychiatr. Scand. 104, 117-121. https://doi.org/10.1034/j.1600-0447.2001.00243.x

Turecki, G., Brent, D.A., 2016. Suicide and suicidal behaviour. Lancet. 
https://doi.org/10.1016/S0140-6736(15)00234-2

Villar, F., Castellano-Tejedor, C., Verge, M., Sánchez, B., Blasco-Blasco, T., 2018. Predictors of Suicide Behavior Relapse in Pediatric Population. Span. J. Psychol. https://doi.org/10.1017/sjp.2018.7

Wang, Y., Bhaskaran, J., Sareen, J., Bolton, S.L., Chateau, D., Bolton, J.M., 2016. Clinician prediction of future suicide attempts: A longitudinal study. Can. J. Psychiatry 61, 428-432. https://doi.org/10.1177/0706743716645287

World Health Organization, 2014. Preventing suicide: A global imperative. Geneva: World Health Organization.

Yip, P.S.F., Hawton, K., Liu, Kayuet, Liu, Kwong sun, Ng, P.W.L., Kam, P. man, Law, Y. wa, Wong, T. wai, 2011. A study of deliberate self-harm and its repetitionamong patients presenting to anemergency department. Crisis 32, 217-224. https://doi.org/10.1027/0227-5910/a000069

Zahl, D.L., Hawton, K., 2004. Repetition of deliberate self-harm and subsequent suicide risk: Longterm follow-up study of 11583 patients. Br. J. Psychiatry 185, 70-75. https://doi.org/10.1192/bjp.185.1.70

Zalsman, G., Hawton, K., Wasserman, D., van Heeringen, K., Arensman, E., Sarchiapone, M., Carli, V., Höschl, C., Barzilay, R., Balazs, J., Purebl, G., Kahn, J.P., Sáiz, P.A., Lipsicas, C.B., Bobes, J., Cozman, D., Hegerl, U., Zohar, J., 2016. Suicide prevention strategies revisited: 10-year systematic review. The lancet. Psychiatry 3, 646-59. https://doi.org/10.1016/S22150366(16)30030-X 


\begin{tabular}{|c|c|c|c|c|c|}
\hline Sample characteristics at the index episode $(n=108)$ & \multicolumn{2}{|r|}{$\mathrm{n}$} & \multicolumn{3}{|c|}{$\%$} \\
\hline Gender (male) & \multicolumn{2}{|c|}{35} & \multicolumn{3}{|c|}{32.4} \\
\hline Married (yes) & \multicolumn{2}{|c|}{59} & \multicolumn{3}{|c|}{54.6} \\
\hline Sociofamiliar support (yes) & \multicolumn{2}{|r|}{89} & \multicolumn{3}{|c|}{82.4} \\
\hline Employed (yes) & \multicolumn{2}{|c|}{38} & \multicolumn{3}{|c|}{35.2} \\
\hline History of physical or sexual abuse (yes) & \multicolumn{2}{|r|}{14} & \multicolumn{3}{|c|}{13.0} \\
\hline Family history of suicide (yes) & \multicolumn{2}{|r|}{6} & \multicolumn{3}{|c|}{5.6} \\
\hline Previous suicide tentative (yes) & \multicolumn{2}{|c|}{53} & \multicolumn{3}{|c|}{49.1} \\
\hline Previous contact with mental health outpatient units (yes) & \multicolumn{2}{|c|}{69} & \multicolumn{3}{|c|}{63.9} \\
\hline Somatic disease comorbidity (yes) & \multicolumn{2}{|c|}{28} & \multicolumn{3}{|c|}{25.9} \\
\hline Substance use (yes) & \multicolumn{2}{|c|}{16} & \multicolumn{3}{|c|}{14.8} \\
\hline Psychiatric diagnosis (yes) & \multicolumn{2}{|c|}{83} & \multicolumn{3}{|c|}{76.9} \\
\hline \multicolumn{6}{|l|}{ STB index: } \\
\hline - Suicidal ideation & \multicolumn{2}{|c|}{47} & \multicolumn{3}{|c|}{43.5} \\
\hline - Suicide attempt: & \multicolumn{2}{|c|}{61} & \multicolumn{3}{|c|}{56.5} \\
\hline - Drug overdose & \multicolumn{2}{|r|}{44} & \multicolumn{3}{|c|}{$72.1^{*}$} \\
\hline - Cutting & & 8 & & $13.1^{*}$ & \\
\hline - Hanging & & 4 & & $6.6^{*}$ & \\
\hline - Self-defenestration & & 1 & & $1.6^{*}$ & \\
\hline - Gas asphyxiation & & 1 & & $1.6^{*}$ & \\
\hline - Others & & 3 & & $4.9^{*}$ & \\
\hline Depressive mood (yes) & & 22 & & 20.4 & \\
\hline Rational thinking loss (yes) & & 8 & & 7.4 & \\
\hline STB planning (yes) & & 12 & & 11.1 & \\
\hline Organised suicide plan (yes) & & 12 & & 11.1 & \\
\hline Hospitalization after STB episode (yes) & & 20 & & 18.5 & \\
\hline & Mean & Median & SD & Max & Min \\
\hline Age & 42.80 & 41.50 & 14.53 & 84 & 16 \\
\hline Number of previous suicide tentatives & 1.04 & 0 & 1.57 & 10 & 0 \\
\hline SAD Persons & 2.66 & 3.00 & 1.30 & 6 & 0 \\
\hline
\end{tabular}

Table 1. Sample characteristics at index episode of STB.

Max: maximum; min: minimum; STB: suicidal thoughts and behaviors; SD: standard deviation.

*Percentages calculated over the number of suicide attempt $(\mathrm{N}=61)$ 


\begin{tabular}{|c|c|c|c|c|}
\hline Predictor factor STB-R $(\mathrm{N}=34)$ & STB-R, n (\%) & Adjusted HR & $95 \% \mathrm{Cl}$ & $p$ \\
\hline Age & & 1.005 & $0.971-1.039$ & 0.791 \\
\hline \multicolumn{5}{|l|}{ Gender } \\
\hline Female & $23(67.65)$ & 1 & & \\
\hline Male & $11(32.35)$ & 0.722 & $0.311-1.677$ & 0.449 \\
\hline \multicolumn{5}{|l|}{ Sociofamiliar support } \\
\hline Yes & 27 (79.41) & 1 & & \\
\hline No & $7(20.59)$ & 2.306 & $0.880-6.041$ & 0.089 \\
\hline \multicolumn{5}{|l|}{ Marital status } \\
\hline Married/in union & $18(52.94)$ & 1 & & \\
\hline Alone & $16(47.06)$ & 1.376 & $0.615-3.081$ & 0.437 \\
\hline \multicolumn{5}{|l|}{ Employment } \\
\hline Yes & $11(32.35)$ & 1 & & \\
\hline No & $23(67.65)$ & 2.313 & $0.756-7.070$ & 0.141 \\
\hline \multicolumn{5}{|l|}{ Family history of suicide } \\
\hline No & 33 (97.06) & 1 & & \\
\hline Yes & $1(2.94)$ & 0.738 & $0.092-5.947$ & 0.776 \\
\hline \multicolumn{5}{|l|}{ Substance use } \\
\hline No & $28(82.35)$ & 1 & & \\
\hline Yes & $6(17.65)$ & 1.097 & $0.362-3.320$ & 0.870 \\
\hline \multicolumn{5}{|l|}{ Psychiatric diagnosis } \\
\hline No & $5(14.71)$ & 1 & & \\
\hline Yes & 29 (85.29) & 1.021 & $0.288-3.624$ & 0.974 \\
\hline \multicolumn{5}{|l|}{ Physical disease } \\
\hline No & $26(76.47)$ & 1 & & \\
\hline Yes & $8(23.53)$ & 1.202 & $0.453-3.190$ & 0.712 \\
\hline \multicolumn{5}{|l|}{ Trauma history } \\
\hline No & $30(88.24)$ & 1 & & \\
\hline Yes & 4 (11.76) & 0.401 & $0.125-1.288$ & 0.125 \\
\hline Number of previous suicide attempts & & 1.316 & $1.046-1.657$ & $0.019 *$ \\
\hline \multicolumn{5}{|l|}{ Index STB: SI vs SA } \\
\hline SI & $18(52.94)$ & 1 & & \\
\hline SA & $16(47.06)$ & 0.649 & $0.307-1.372$ & 0.258 \\
\hline \multicolumn{5}{|l|}{ Planning of index STB } \\
\hline No & $31(91.18)$ & 1 & & \\
\hline Yes & $3(8.82)$ & 0.599 & $0.151-2.374$ & 0.465 \\
\hline \multicolumn{5}{|l|}{ Hospital admission at index } \\
\hline No & $25(73.53)$ & 1 & & \\
\hline Yes & $9(26.47)$ & 2.206 & $0.794-6.128$ & 0.129 \\
\hline \multicolumn{5}{|l|}{ Rational thinking loss at index } \\
\hline No & $32(94.12)$ & 1 & & \\
\hline Yes & $2(5.88)$ & 3.290 & $0.503-21.524$ & 0.214 \\
\hline \multicolumn{5}{|l|}{ Depression at index } \\
\hline No & $28(82.35)$ & 1 & & \\
\hline Yes & $6(17.65)$ & 0.953 & $0.302-3.014$ & 0.935 \\
\hline \multicolumn{5}{|l|}{ ED visit for psychiatric reasons during f-up } \\
\hline No & $14(41.18)$ & 1 & & \\
\hline Yes & $20(58.82)$ & 6.495 & $2.967-14.218$ & $<0.001^{* *}$ \\
\hline \multicolumn{5}{|c|}{ Outpatient at Mental Health Unit during f-up } \\
\hline No & $1(2.94)$ & 1 & & \\
\hline Yes & $33(97.06)$ & 12.783 & $1.543-105.934$ & $0.018^{*}$ \\
\hline
\end{tabular}

Table 2. Adjusted Hazard ratio of STB-R (SA+SI-R) during one-year follow-up. In dichotomic variables, HR takes a value of "one" in the reference category. Abbreviations: ED: Emergency Department; HR: Hazard Ratio; R: Recurrence; STB: suicidal thoughts and behaviors; SA: suicide attempt; SI: suicidal ideation.

* Significance level $\leq 0.05 ;{ }^{* *}$ Significance level $\leq 0.01$ 


\begin{tabular}{|c|c|c|c|c|}
\hline Predictor factor $\mathrm{SA}-\mathrm{R}(\mathrm{N}=25)$ & SA-R, n (\%) & Adjusted HR & $95 \% \mathrm{Cl}$ & $p$ \\
\hline Age & & 0.993 & $0.954-1.033$ & 0.725 \\
\hline \multicolumn{5}{|l|}{ Gender } \\
\hline Female & $16(64)$ & 1 & & \\
\hline Male & $9(36)$ & 0.960 & $0.367-2.512$ & 0.933 \\
\hline \multicolumn{5}{|l|}{ Sociofamiliar support } \\
\hline Yes & $19(76)$ & 1 & & \\
\hline No & $6(24)$ & 2.171 & $0.761-6.192$ & 0.147 \\
\hline \multicolumn{5}{|l|}{ Marital status } \\
\hline Married/in union & $13(52)$ & 1 & & \\
\hline Alone & $12(48)$ & 1.689 & $0.610-4.678$ & 0.314 \\
\hline \multicolumn{5}{|l|}{ Employment } \\
\hline Yes & $8(32)$ & 1 & & \\
\hline No & $17(68)$ & 3.600 & $0.998-12.989$ & $0.050^{*}$ \\
\hline \multicolumn{5}{|l|}{ Family history of suicide } \\
\hline No & $25(100)$ & 1 & & \\
\hline Yes & $0(0)$ & 0.000 & $0.000-\wedge$ & 0.984 \\
\hline \multicolumn{5}{|l|}{ Substance use } \\
\hline No & $19(76)$ & 1 & & \\
\hline Yes & $6(24)$ & 1.995 & $0.586-6.795$ & 0.269 \\
\hline \multicolumn{5}{|l|}{ Psychiatric disease } \\
\hline No & $4(16)$ & 1 & & \\
\hline Yes & $21(84)$ & 0.368 & $0.075-1.805$ & 0.218 \\
\hline \multicolumn{5}{|l|}{ Physical disease } \\
\hline No & $18(72)$ & 1 & & \\
\hline Yes & $7(28)$ & 1.610 & $0.516-5.022$ & 0.412 \\
\hline \multicolumn{5}{|l|}{ Trauma history } \\
\hline No & $21(84)$ & 1 & & \\
\hline Yes & $4(16)$ & 0.779 & $0.219-2.778$ & 0.701 \\
\hline Number of previous suicide attempts & & 1.314 & $1.032-1.673$ & $0.027^{*}$ \\
\hline \multicolumn{5}{|l|}{ Index STB: SI vs SA } \\
\hline SI & $10(40)$ & 1 & & \\
\hline SA & $15(60)$ & 1.657 & $0.691-3.974$ & 0.258 \\
\hline \multicolumn{5}{|l|}{ Planning of index STB } \\
\hline No & $23(92)$ & 1 & & \\
\hline Yes & $2(8)$ & 0.458 & $0.087-2.395$ & 0.355 \\
\hline \multicolumn{5}{|l|}{ Hospital admission at index } \\
\hline No & $16(64)$ & 1 & & \\
\hline Yes & $9(36)$ & 4.467 & $1.572-12.692$ & $0.005^{* *}$ \\
\hline \multicolumn{5}{|l|}{ Rational thinking loss at index } \\
\hline No & $23(92)$ & 1 & & \\
\hline Yes & $2(8)$ & 0.575 & $0.086-3.818$ & 0.566 \\
\hline \multicolumn{5}{|l|}{ Depression at index } \\
\hline No & $20(80)$ & 1 & & \\
\hline Yes & $5(20)$ & 2.333 & $0.599-9.084$ & 0.222 \\
\hline \multicolumn{5}{|c|}{ ED visit for psychiatric reasons during f-up } \\
\hline No & $13(52)$ & 1 & & \\
\hline Yes & $12(48)$ & 3.305 & $1.375-7.946$ & $0.008^{* *}$ \\
\hline \multicolumn{5}{|c|}{ Outpatient at Mental Health Unit during f-up } \\
\hline No & $1(4)$ & 1 & & \\
\hline Yes & $24(96)$ & 11.850 & $1.317-106.663$ & $0.027^{*}$ \\
\hline
\end{tabular}

Table 3. Adjusted Hazard ratio of SA-R during one-year follow-up. The comparison is made between those who had at least one SA-R and the rest of the sample (encompassing those who recurred with $\mathrm{SI}$ and those who did not recur at all). In dichotomic variables, HR takes a value of "one" in the reference category. Abbreviations: ED: Emergency Department; HR: Hazard Ratio; R: Recurrence; SA: suicide attempt; SI: suicidal ideation; STB: suicidal thoughts and behaviors. * Significance level $\leq 0.05 ; *$ Significance level $\leq 0.01$

^Unable to estimate upper interval as there are zero cases of family history of suicide among patients with recurrent suicide attempt. 


\begin{tabular}{|c|c|c|c|c|}
\hline Predictor factor SI-R (N=11) & SI-R, n (\%) & Adjusted HR & $95 \% \mathrm{Cl}$ & $p$ \\
\hline Age & & 1.081 & $0.986-1.186$ & 0.097 \\
\hline \multicolumn{5}{|l|}{ Gender } \\
\hline Female & $8(80)$ & 1 & & \\
\hline Male & $2(20)$ & 0.203 & $0.024-1.715$ & 0.143 \\
\hline \multicolumn{5}{|l|}{ Sociofamiliar support } \\
\hline Yes & $80(80)$ & 1 & & \\
\hline No & $2(20)$ & 1.293 & $0.130-12.817$ & 0.826 \\
\hline \multicolumn{5}{|l|}{ Marital status } \\
\hline Married/in union & $5(50)$ & 1 & & \\
\hline Alone & $5(50)$ & 2.279 & $0.408-12.732$ & 0.348 \\
\hline \multicolumn{5}{|l|}{ Employment } \\
\hline Yes & $3(30)$ & 1 & & \\
\hline No & $7(70)$ & 0.934 & $0.161-5.419$ & 0.939 \\
\hline \multicolumn{5}{|l|}{ Substance use } \\
\hline No & $9(90)$ & 1 & & \\
\hline Yes & $1(10)$ & 1.938 & $0.096-39.237$ & 0.666 \\
\hline \multicolumn{5}{|l|}{ Psychiatric disease } \\
\hline No & $1(10)$ & 1 & & \\
\hline Yes & $9(90)$ & 20.050 & $0.880-456.891$ & 0.060 \\
\hline \multicolumn{5}{|l|}{ Physical disease } \\
\hline No & $9(90)$ & 1 & & \\
\hline Yes & $1(10)$ & 0.089 & $0.007-1.144$ & 0.063 \\
\hline \multicolumn{5}{|l|}{ Trauma history } \\
\hline No & $10(100)$ & 1 & & \\
\hline Yes & $0(0)$ & 0.464 & $0.044-4.919$ & 0.524 \\
\hline Number of previous suicide attempts & & 1.058 & $0.750-1.494$ & 0.747 \\
\hline \multicolumn{5}{|l|}{ Index STB: SI vs SA } \\
\hline $\mathrm{SI}$ & $8(80)$ & 1 & & \\
\hline SA & $2(20)$ & 0.064 & $0.006-0.643$ & $0.020^{*}$ \\
\hline \multicolumn{5}{|l|}{ Planning of index STB } \\
\hline No & $9(90)$ & 1 & & \\
\hline Yes & $1(10)$ & 8.294 & $0.399-172.516$ & 0.172 \\
\hline \multicolumn{5}{|l|}{ Rational thinking loss at index } \\
\hline No & $10(100)$ & 1 & & \\
\hline Yes & $0(0)$ & 0.000 & $0.000-\wedge$ & 0.991 \\
\hline \multicolumn{5}{|l|}{ Depression at index } \\
\hline No & $9(90)$ & 1 & & \\
\hline Yes & $1(10)$ & 0.019 & $0.001-0.681$ & $0.030^{*}$ \\
\hline \multicolumn{5}{|l|}{ ED visit for psychiatric reasons during f-up } \\
\hline No & $1(10)$ & 1 & & \\
\hline Yes & $9(90)$ & 71.059 & $4.637-1089.044$ & $0.002^{* *}$ \\
\hline
\end{tabular}

Table 4. Adjusted Hazard ratio of SI-R during one-year follow-up. The comparison is made between those who had at least one SI-R and the rest of the sample (encompassing those who recurred with SA and those who did not recur at all). In dichotomic variables, HR takes a value of "one" in the reference category. Abbreviations: ED: Emergency Department; HR: Hazard Ratio; R: Recurrence; SA: suicide attempt; SI: suicidal ideation; STB: suicidal thoughts and behaviors. * Significance level $\leq 0.05$; ${ }^{* *}$ Significance level $\leq 0.01$

$\wedge$ Unable to estimate upper interval as there are zero cases of rational thinking loos at index among patients with recurrent suicidal ideation. 


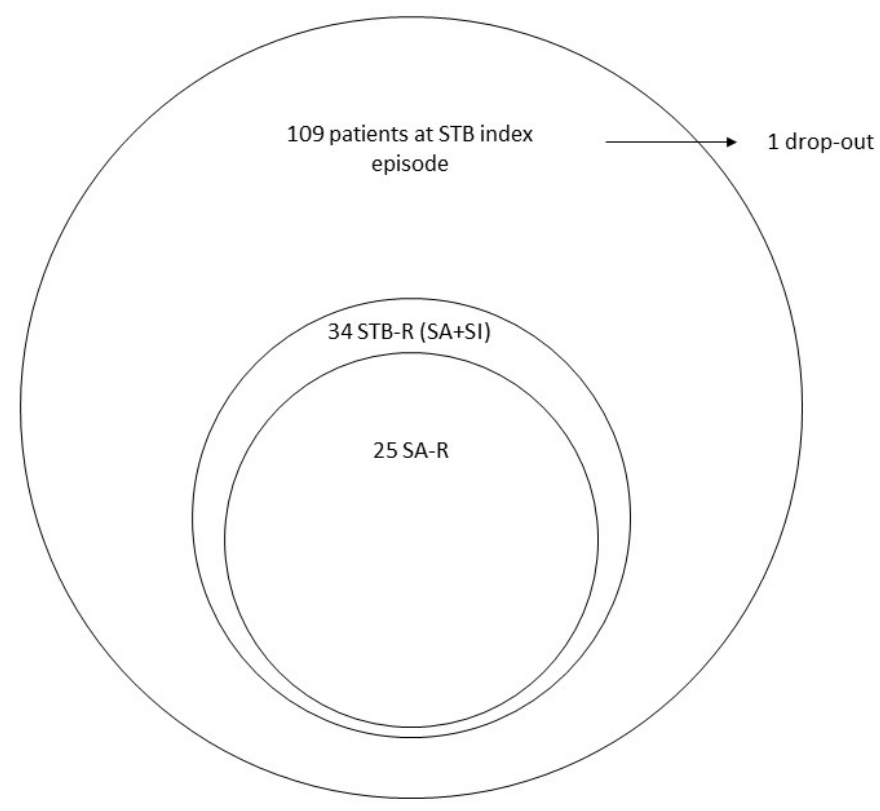

Figure 1. Patient's profile.

R: recurrence; STB: suicidal thoughts and behaviors; SA: suicide attempt; SI: suicidal ideation. 

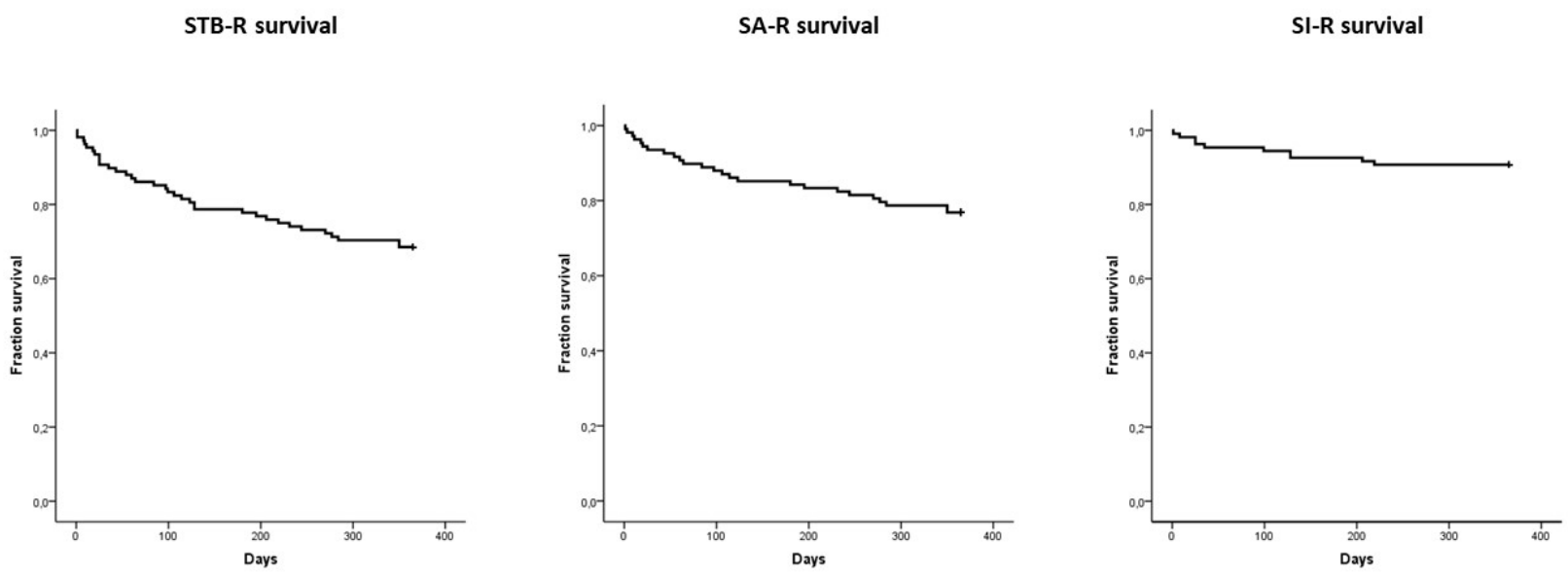

Figure 2. Survival curve for recurrence in suicide thoughts and behaviors (STB-R), suicide attempt recurrence (SA-R) and suicidal ideation recurrence (SI-R) during the follow-up.

R: recurrence; STB: suicide thoughts and behaviors; SA: suicide attempt; SI: suicidal ideation 
3A: Previous suicide attempts

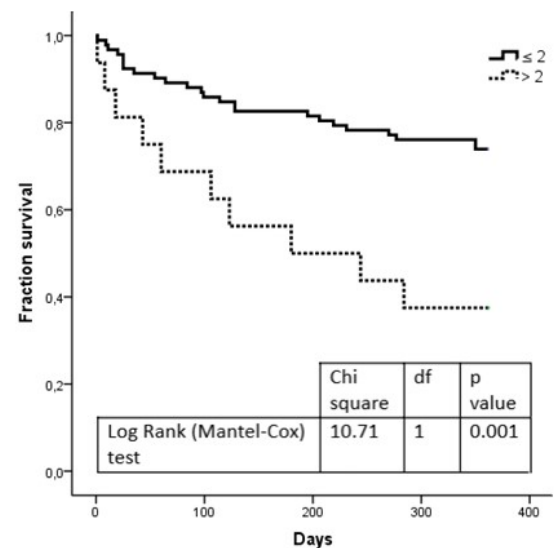

3B: ED visits for other psychiatric reasons during f-up $3 \mathrm{C}$ : Contact with mental health outpatient units during f-up

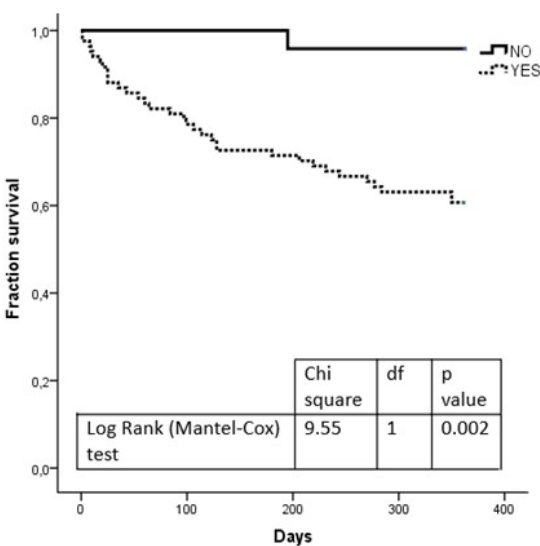

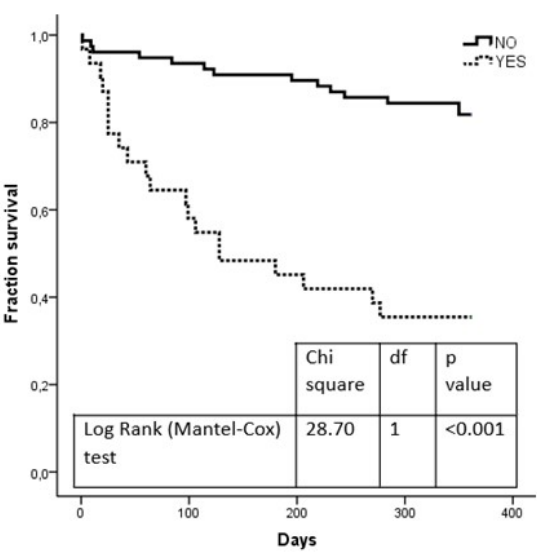

Figure 3. Comparison of time to recurrence for suicidal thoughts and behaviors (STB-R) according to significant predictors.

ED: Emergency Department; f-up: follow-up 


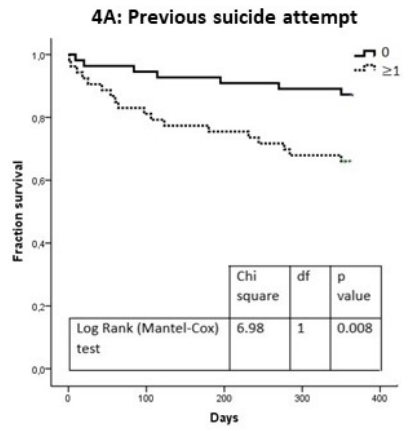

4C: ED visit for psychiatric reasons during f-up

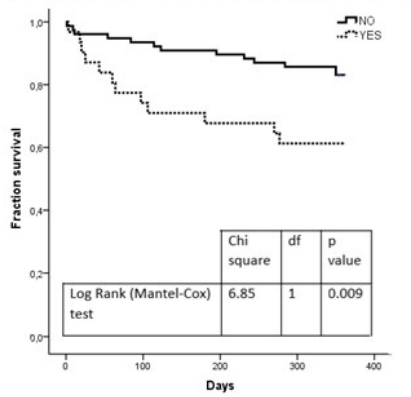

4B: Hospital admission at index

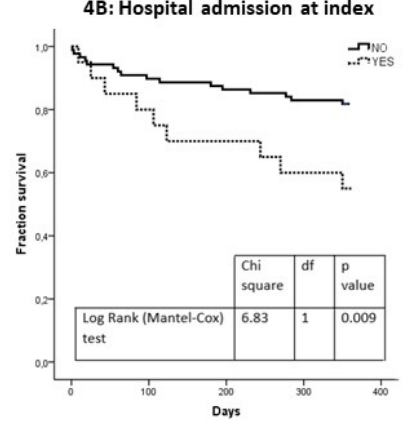

4D: Contact with mental health outpatient units during f-up

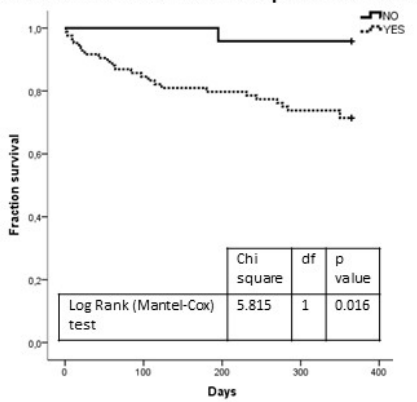

Figure 4. Comparison of time for suicide attempt recurrence (SA-R) during one year of follow-up according to significant predictors.

ED: Emergency Department; f-up: follow-up 

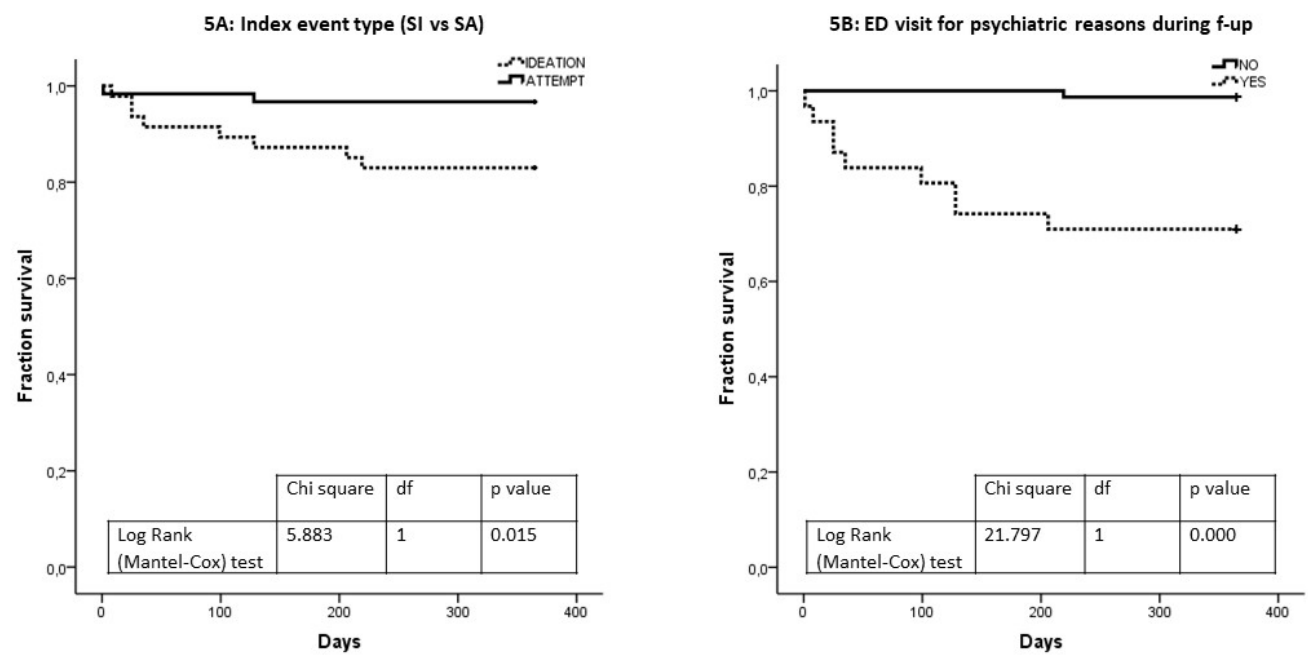

Figure 5. Comparison of time for suicidal ideation recurrence (SI-R) during one year of follow-up according to significant predictors.

ED: Emergency Department; f-up: follow-up; SA: suicide attempt; SI. Suicidal ideation. 